Check for updates

Cite this: RSC Adv., 2019, 9, 16183

Received 24th April 2019 Accepted 16th May 2019

DOI: $10.1039 / \mathrm{c} 9 \mathrm{ra} 03032 \mathrm{~h}$

rsc.li/rsc-advances

\title{
A three-dimensional metal-organic framework for a guest-free ultra-low dielectric material $\dagger$
}

\author{
W. Xu, tb S. S. Yu, ta H. Zhangt: and H. B. Duan (D)*ac \\ A three-dimensional metal-organic framework compound $\left[\mathrm{NH}_{2}\left(\mathrm{CH}_{3}\right)_{2}\right]_{2}\left[\mathrm{Zn}_{3}(\mathrm{bpdc})_{4}\right] \cdot 3 \mathrm{DMF}$ (1) shows \\ two step dielectric relaxation and its guest-free framework $\left(1^{\prime}\right)$ possesses an ultra-low $\kappa$ value of 1.80 \\ (at $100 \mathrm{kHz}$, it is the lowest value for MOFs reported to date) over a wide temperature range and high \\ thermal stability.
}

The design and synthesis of low dielectric constant (low- $\kappa$ ) materials has been a subject of interest in terms of their potential for use in high performance electronic devices. Materials with extremely low-dielectric constants have been targeted as interlayer dielectrics (ILD) because they decrease the cross-talk noise, propagation delay, and power dissipation in most electronic components. ${ }^{1-5}$ Indeed, the search for new low$\kappa$ materials replacing silicon dioxide $\left(\mathrm{SiO}_{2}\right)$ as an ILD has always been dictated by industrial needs, resulting in a strong connection between fundamental research and technology. ${ }^{6}$ Many materials have been proposed and studied as potential candidates; two major classes are dense organic polymers and porous inorganic-based materials. Some dense organic polymers could have $\kappa$ below 2.2, but they suffer from concerns of low thermal stability and thermal conductivity. For porous inorganic-based low- $\kappa$ materials, sol-gel silica, doped oxides and mesoporous silica have been extensively studied. ${ }^{7}$ but its low mechanical strength, wide pore size distribution, and hydrophilicity have been cited as concerns.

As air or vacuums have the lowest dielectric constant $(\kappa=$ 1.01), the partial replacement of solid network with air or a vacuum appears to be the more intuitive and direct option to the development of new low- $\kappa$ ILD materials. Thus, as per the International Technology Roadmap for Semiconductors (ITRS), robust porous materials and air gap structures will become target low- $\kappa$ materials in the near future. ${ }^{8}$ Metal-organic frameworks (MOFs) with a well-defined monodisperse porosity, large surface area, ultra-low densities, high stability and easy tunability of the surface and structural properties have potential

${ }^{a}$ School of Environmental Science, Nanjing Xiaozhuang University, Nanjing, 211171, P. R. China. E-mail: duanhaibao4660@163.com

${ }^{b}$ Department of Chemistry, Huangshan University, Huangshan 245041, P. R. China 'Department of Chemistry and Biochemistry, University of California, Los Angeles, California 90095-1569, USA

$\dagger$ Electronic supplementary information (ESI) available: Experimental details, additional figures, powder XRD, TG and dielectric loss curves. CCDC 1884532. For ESI and crystallographic data in CIF or other electronic format see DOI: 10.1039/c9ra03032h

\$ These authors contributed equally. for meet the demands for use as stable low- $\kappa$ materials. ${ }^{9}$ MOFs have been extensively studied over the past decade for their applications in gas storage, sensors, chemical separation, catalysis, drug delivery and biomedical imaging. ${ }^{10-12}$ However, their electrical properties and applications in microelectronics remain under researched. ${ }^{13}$ MOFs should be stiffer and harder than other low-density amorphous inorganic or organic polymers because of their ordered framework and rigid organic linkers. With tunable structural properties, high porosity, and thermal/mechanical stability, MOFs represent an ideal replacement as an ILD material. Hermann and coworkers presented a brief theoretical model for using MOFs as low- $\kappa$ materials in microelectronics applications. ${ }^{14}$ However, these theoretical calculations did not take into account the orientational and ionic contributions to the molecular polarizability, which drastically contribute to the dielectric constant. These theoretical results encouraged us to search for new MOFs materials with experimentally ultra-low $\kappa$ values.

In this work, we report on the preparation of a MOFs, $\left[\mathrm{NH}_{2}\left(\mathrm{CH}_{3}\right)_{2}\right]_{2}\left[\mathrm{Zn}_{3}(\mathrm{bpdc})_{4}\right] \cdot 3 \mathrm{DMF}$ (1) $\left(\mathrm{H}_{2} \mathrm{bpdc}=4,4^{\prime}\right.$-biphenyldicarboxylic acid), which have 3D frameworks with high thermal stability (Fig. S1 $\dagger$ ) and a ultra-low $\kappa$ values of its guestfree sample $\mathbf{1}^{\prime}$. The $\mathbf{1}^{\prime}$ possesses a very low $\kappa$ values of 1.80 (at 100 $\mathrm{kHz}$ ) and high thermal stability at temperatures up to $360^{\circ} \mathrm{C}$ (Fig. S2 $\dagger$ ), making it a potential candidate for use as an ILD. To the best of our knowledge, to date, the $\kappa$ values of $\mathbf{1}^{\prime}$ is the lowest value for MOFs reported. Furthermore, compound 1 shows dielectric relaxation and anomalies in the temperature range of $35-140{ }^{\circ} \mathrm{C}$. Dielectric relaxation and anomalies of 1 is related to reorientation of the dipole moment of surface absorbed water and guest DMF molecules, respectively.

The compound 1 was obtained from the solvothermal reaction of $\mathrm{Zn}\left(\mathrm{NO}_{3}\right)_{2} \cdot 6 \mathrm{H}_{2} \mathrm{O}, \mathrm{H}_{2}$ bpdc and $\left[\mathrm{NH}_{2}\left(\mathrm{CH}_{3}\right)_{2}\right] \mathrm{Cl}$ in DMF. Xray crystallographic analysis reveals that it crystallizes in the space group $P n a 2_{1} . \S$ The asymmetric unit contains of three

$\S$ Crystal data for compound 1, space group Pna2 ${ }_{1}, a=24.7046(12) \AA, b=$ 14.5230(9) ̊, $c=22.3879(12) \AA, \alpha=\beta=\gamma=90.00^{\circ}, V=8032.4(8) \AA^{3}, Z=4, D_{\mathrm{c}}$ $=1.033 \mathrm{~g} \mathrm{~cm}^{-3}, \mathrm{Mu}=0.939 \mathrm{~mm}$ (see ESI). 
crystallographically distinct $\mathrm{Zn}^{2+}$ ions, four deprotonated bpdc $^{2-}$ ligands, two $\left[\mathrm{NH}_{2}\left(\mathrm{CH}_{3}\right)_{2}\right]^{+}$ions and three free DMF molecules. Three crystallographically independent $\mathrm{Zn}^{2+}$ ions have two coordination modes (Fig. 1a). The $\mathrm{Zn}(1)$ and $\mathrm{Zn}(3)$ adopts a four-coordinated and formed slightly distorted tetrahedral geometry, and the $\mathrm{Zn}(2)$ adopts a six-coordinated geometry. $\mathrm{O} 13$ and $\mathrm{O} 16$ atoms originated from monodentate coordination of the $\mathrm{bpdc}^{2-}$ ligands and the other oxygen atoms are coordinated by $\mu 2$-modes bpdc ${ }^{2-}$ ligands to $\mathrm{Zn}^{2+}$ ions. The shortest and longest Zn-O distance is 1.881(10) and 2.088(9) $\AA$, respectively. Each $\mathrm{Zn}(2)$ atom is connected $\mathrm{Zn}(1)$ atom and $\mathrm{Zn}(3)$ atom by three bridged bidentate bpdc $^{2-}$ ligands to form trinuclear building blocks. As shown in Fig. 1b, trinuclear building blocks are further linked together by bpdc ${ }^{2-}$ ligands make up the 3D anionic framework with two different channels, and the channels is occupied by $\left[\mathrm{NH}_{2}\left(\mathrm{CH}_{3}\right)_{2}\right]^{+}$ions and disordered DMF guest molecules. Parallel to the $a c$ plane, the monodentate bpdc $^{2-}$ ligands bridge trinuclear building blocks to afford layers stacking, and the layers are pillared by bidentate bpdc ${ }^{2-}$ ligands to give rise to a regular 3D network (Fig. 1c), and channel

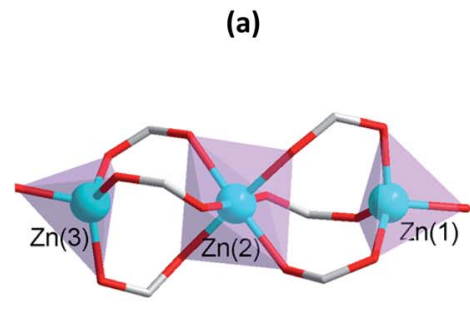

(b)
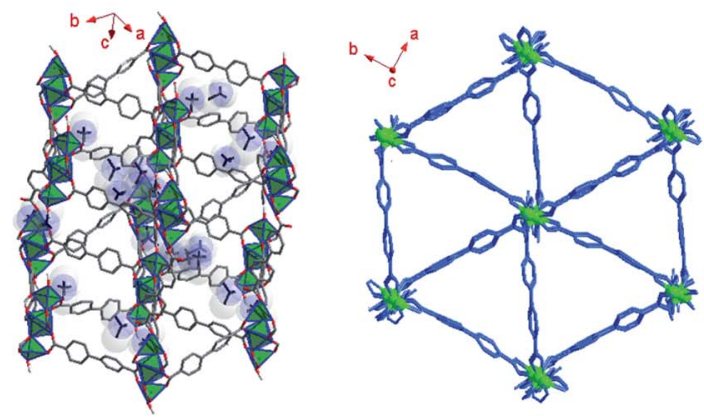

(e)

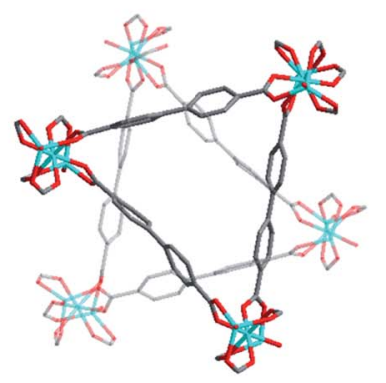

Fig. 1 Structure of 1 (a) trinuclear metal cluster building blocks; (b) 3D anionic framework with two different channels; (c) regular channel along the $b$-axis direction; (d) the triangle cage along the $c$-axis direction; (e) two independent interpenetrated triangle cage. dimensions is about $13 \times 18 \AA$ along the $b$-axis direction. The triangle cage was formed along the $c$-axis direction with small channel (Fig. 1d). Overall, two individual triangle cage are independent interpenetrated to form the entire framework of $\mathbf{1}$ (Fig. 1e). It should be noted that although the framework of $\mathbf{1}$ is interpenetration networks, it is still highly porous. After the removal of solvent molecules in the channels, the accessible volume of 1 is $40.2 \%$.

The temperature dependent dielectric properties were investigated in the temperature rang of $30-135^{\circ} \mathrm{C}$, and two-step dielectric relaxation were observed. As show in Fig. 2a, it is clear that compound 1 shows the first step dielectric relaxation in the temperature range of $30-80{ }^{\circ} \mathrm{C}$. When 1 was heated from 30 to $37^{\circ} \mathrm{C}$, the dielectric constant progressive increased and reaches a maximum of 174.4 at $10^{3} \mathrm{~Hz}$. Further increase in temperature results in the dielectric constant of $\mathbf{1}$ slowly decreasing and dielectric peak disappears. The first step dielectric relaxation is due to the relaxation of absorbed water molecules in the sample surface. The dielectric relaxation signal was not observed in the cooling process (from $95{ }^{\circ} \mathrm{C}$ to $30{ }^{\circ} \mathrm{C}$ ) for losing surface water (Fig. $2 \mathrm{~b}$ ). The $\kappa$ value is directly related to the polarization phenomena. The higher the polarization, the greater the increase in $\kappa$ value will be. Usually, the MOF materials with low $\kappa$ value feature the reorientational motions of polar guest molecules being restricted at low temperature or frameworks solvent-free. However, for $\mathbf{1}$, the thermally assisted dynamical dipole motion due to polar DMF molecules is appeared. The guest molecules get enough excitation thermal energy to be able to obey the change under the external electric field more easily in the high temperature regime, and the reorientational dynamics of guest molecules is activated above $105{ }^{\circ} \mathrm{C}$. This in return enhances their contribution to the polarization leading to an sharp increase of dielectric permittivity value. At $f=10^{5} \mathrm{~Hz}$, the dielectric constant reaches a maximum of 237 , and then sharply decreased when the temperature increased. In the following cooling process, a very low $\kappa$ value was observed and no dielectric relaxation was occurred (Fig. 2c). The second step dielectric relaxation at different frequency are shown in Fig. 2d, which can be ascribed to the guest polar DMF reorientational motions. In addition, the dielectric loss values shows similar features in the selected frequency range (Fig. S3 $†$ ).

Removing polar guest molecules from the framework may be decreases the polarization and the possibility of any type of hydrogen bonding or ionic interactions between the framework and guest molecular, hence, the $\kappa$ value will also decreases. The guest-free sample $\mathbf{1}^{\prime}$ were obtained by simply heating method. The PXRD patterns of the $\mathbf{1}$ match well with the $\mathbf{1}^{\prime}$ (Fig. S4 $\dagger$ ), thus demonstrating the phase were unaltered. The dielectric properties of guest-free sample $\mathbf{1}^{\prime}$ were investigated. As shown in Fig. 3, after removing the polar DMF molecules, a very low $\kappa$ value of 1.78 at $100 \mathrm{kHz}$ at $40^{\circ} \mathrm{C}$ with a low dielectric loss $(0.005)$ was observed (Fig. S5 $\dagger$ ). It is very interesting as the temperature increase from 40 to $130{ }^{\circ} \mathrm{C}, \kappa$ value increases very slowly. $\kappa$ value is 1.99 at $130^{\circ} \mathrm{C}$. With the ac electric field frequency increasing, the $\kappa$ value slightly decrease (Fig. 3a). It is noteworthy that, to date, dielectric investigations of MOFs have received relatively little attention, although a few exciting examples have been reported. Only a limited number of MOFs have been reported to 
(a)

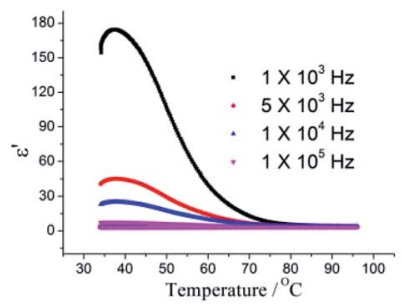

(c)

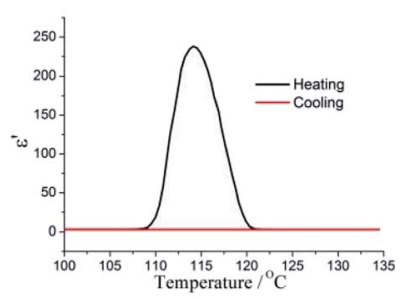

(b)

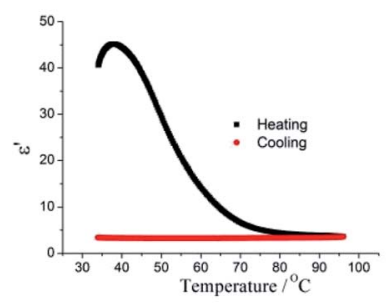

(d)

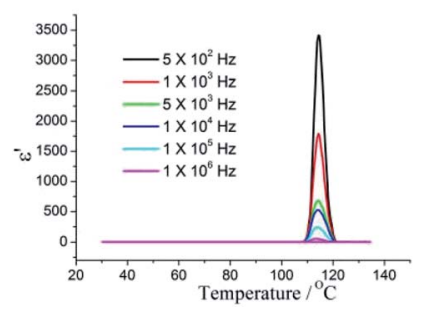

Fig. 2 (a) Temperature-dependent real part dielectric constant $\left(\varepsilon^{\prime}\right)$ in the temperature range of $30-95^{\circ} \mathrm{C}$ at selected frequency of 1 ; (b) plots of $\varepsilon^{\prime}$ vs. $T$ in the $30-95^{\circ} \mathrm{C}$ range at $5 \times 10^{3} \mathrm{~Hz}$ with the heating (black dot) and cooling models (red dot); (c) plots of $\varepsilon^{\prime}$ vs. $T$ in the $100-135^{\circ} \mathrm{C}$ range at $10^{5} \mathrm{~Hz}$ with the heating (black line) and cooling models (red line; (d) temperature-dependent $\varepsilon^{\prime}$ in the temperature range of 30$135^{\circ} \mathrm{C}$.

possess ultra-low $\kappa$ value. ${ }^{15,16}$ The ultra-low $\kappa$ values for a few MOFs are shown in Table S2. $\dagger^{17}$ To the best of our knowledge, the $\kappa$ values of $\mathbf{1}^{\prime}$ is the lowest value for MOFs reported. From the published paper and our results, to obtained the ultra-low $\kappa$ MOFs, ligands should have high symmetry and small polarity and polar guest molecular should be avoid. Furthermore, some small counter ions could be decrease $\kappa$ values. As the vacuum has the lowest dielectric constant, thus, $\kappa$ values can be reduced significantly by increasing porosity of MOFs. High thermal stability and MOFs thin-film growth are required for the practical applications of ultra-low $\kappa$ MOFs in microelectronics. ZIF-8 films with $\kappa$ value of 2.4 were deposited on silicon wafers and characterized in order to assess their potential as future insulators (low- $\kappa$ dielectrics) in microelectronics. ${ }^{18} \mathrm{We}$ recently reported a hydrogen bonding MOFs $\left[\mathrm{Zn}\left(\mathrm{H}_{2} \mathrm{EIDA}\right)_{2}\left(\mathrm{H}_{2} \mathrm{O}\right)\right] \cdot 2 \mathrm{DMF}$, which exhibited low- $\kappa$ behaviour, but its thermal stability was not perfect.

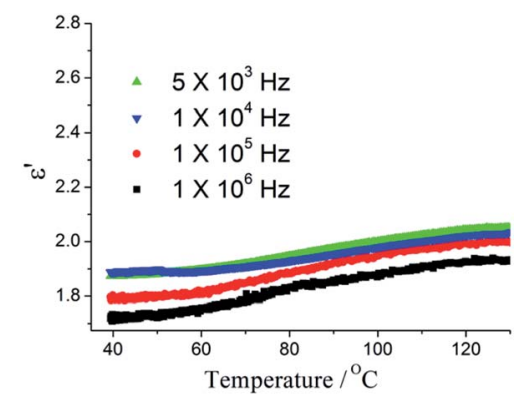

Fig. 3 Temperature-dependent real part dielectric constant $\left(\varepsilon^{\prime}\right)$ at selected frequency of $\mathbf{1}^{\prime}$.

\section{Conclusions}

In conclusion, we have presented a 3D MOFs $\left[\mathrm{NH}_{2}\left(\mathrm{CH}_{3}\right)_{2}\right]_{2}[-$ $\left.\mathrm{Zn}_{3}(\mathrm{bpdc})_{4}\right] \cdot 3 \mathrm{DMF}$ (1) and its guest-free framework ( $\left.\mathbf{1}^{\prime}\right)$. $\mathbf{1}$ possesses two types of cavities, which are occupied by counter ions and the polar solvents DMF, and shows two-step dielectric relaxations which is related to reorientation of the dipole moment of surface absorbed water and guest DMF molecules. Two step relaxation were not observed in guest-free framework $\mathbf{1}^{\prime} . \mathbf{1}^{\prime}$ shows quite low $\kappa$ value (to the best of our knowledge, the $\kappa$ values of $\mathbf{1}^{\prime}$ is the lowest value for MOFs reported to date) and high thermal stability. The ultra-low $\kappa$ value exhibits no significant change over a wide temperature range $\left(40-130{ }^{\circ} \mathrm{C}\right)$. The ultra-low dielectric constant of $\mathbf{1}^{\prime}$ can be attributed to the highly porous and small counter ions in the channels. The foregoing results discussed in this work provide an effective path towards achieving remarkable new applications for dielectric MOFs in the future.

\section{Conflicts of interest}

There are no conflicts to declare.

\section{Acknowledgements}

The authors thanks Natural Science Foundation of JiangSu Province and Natural Science Training Foundation of Nanjing Xiaozhuang University for their financial support (grant No: BK20171125 and 2016NXY12).

\section{Notes and references}

1 W. Volksen, R. D. Miller and G. Dubois, Chem. Rev., 2010, 110, 56.

2 M. D. Allendorf and V. Stavila, CrystEngComm, 2015, 17, 229.

3 P. Ramaswamy, N. E. Wong and G. K. H. Shimizu, Chem. Soc. Rev., 2014, 43, 5913.

4 R. Ameloot, M. Aubrey, B. M. Wiers, A. P. GÖmora-Figueroa, S. N. Patel, N. P. Balsara and J. R. Long, Chem.-Eur. J., 2013, 19, 5533.

5 H. Kitagawa, Nat. Chem., 2009, 1, 689.

6 (a) J. Martin, J. P. Godschalx, M. E. Mills, E. O. Shaffer II and P. H. Townsend, Adv. Mater., 2000, 12, 1769; (b) W. Volksen, R. D. Miller and G. Dubois, Chem. Rev., 2010, 110, 56.

7 (a) R. D. Miller, Science, 1999, 286, 421; (b) S. Seraji, Y. Wu, M. Forbess, S. J. Limmer, T. Chou and G. Cao, Adv. Mater., 2000, 12, 1695; (c) Y. F. Lu, H. Y. Fan, N. Doke, D. A. Loy, R. A. Assink, D. A. LaVan, C. J. Brinker and J. Am, J. Am. Chem. Soc., 2000, 122, 5258; (d) S. Baskaran, J. Liu, K. Domansky, N. Kohler, X. L. Li, C. Coyle, G. E. Fryxell, S. Thevthasan and R. E. Williford, Adv. Mater., 2000, 12, 291. 8 The International Technology Roadmap For Semiconductors (ITRS), 2011 edition.

9 (a) H. Li, M. Eddaoudi, M. O'Keeffe and O. M. Yaghi, Nature, 1999, 402, 276; (b) G. Ferey, Chem. Soc. Rev., 2008, 37, 191; (c) S. Kitagawa, R. Kitaura and S. Noro, Angew. Chem., Int. Ed., 2004, 43, 2334. 
10 S. S. Han, J. L. Mendoza-Cortes and W. A. Goddard, Chem. Soc. Rev., 2009, 38, 1460.

11 (a) R. E. Morris and P. S. Wheatley, Angew. Chem., Int. Ed., 2008, 47, 4966; (b) T. Borjigin, F. Sun, J. Zhang, K. Cai, H. Ren and G. Zhu, Chem. Commun., 2012, 48, 7613; (c) D. Farrusseng, S. Aguado and C. Pinel, Angew. Chem., Int. Ed., 2009, 48, 7502; (d) C. Y. Sun, C. Qin, C. G. Wang, Z. M. Su, S. Wang, X. L. Wang, G. S. Yang, K. Z. Shao, Y. Q. Lan and E. B. Wang, J. Am. Chem. Soc., 2011, 23, 5629.

12 J. Lee, O. K. Farha, J. Roberts, K. A. Scheidt, S. T. Nguyen and J. T. Hupp, Chem. Soc. Rev., 2009, 38, 1450.

13 S. Eslava, L. Zhang, S. Esconjauregui, J. Yang, K. Vanstreels, M. R. Baklanov and E. Saiz, Chem. Mater., 2013, 25, 27.

14 K. Zagorodniy, G. Seifert and H. Hermann, Appl. Phys. Lett., 2010, 97, 251905.

15 (a) W. J. Li, J. Liu, Z. H. Sun, T. F. Liu, J. Lu, S. Y. Gao, C. He, R. Cao and J. H. Luo, Nat. Commun., 2016, 7, 11830; (b) M. Usman, C. H. Lee, D. S. Hung, S. F. Lee, C. C. Wang, T. T. Luo, L. Zhao, M. K. Wu and K. L. Lu, J. Mater. Chem. C, 2014, 2, 3762; (c) S. Eslava, L. Zhang, S. Esconjauregui, J. Yang, K. Vanstreels, M. R. Baklanov and E. Saiz, Chem. Mater., 2013, 25, 27.
16 (a) S. Mendiratta, M. Usman, T. T. Luo, B. C. Chang, S. F. Lee, Y. C. Lin and K. L. Lu, Cryst. Growth Des., 2014, 14, 1572; (b) S. Mendiratta, M. Usman, T. T. Luo, S. F. Lee, Y. C. Lin and K. L. Lu, CrystEngComm, 2014, 16, 6309; (c) S. S. Yu, G. J. Yuan and H. B. Duan, RSC Adv., 2015, 5, 4521345216; (d) F. Wang, C. Y. Ni, Q. Liu, F. L. Li, J. Shi, H. X. Lia and J. P. Lang, Chem. Commun., 2013, 49, 9248; (e) P. Yang, X. He, M. X. Li, Q. Ye, J. Z. Ge, Z. X. Wang, S. R. Zhu, M. Shao and H. L. Cai, J. Mater. Chem., 2012, 22, 2398.

17 (a) M. Usman, S. Mendiratta and K. L. Lu, ChemElectroChem, 2015, 2, 786; (b) P. C. Guo, Z. Chu, X. M. Ren, W. H. Ning and W. Jin, Dalton Trans., 2013, 42, 6603; (c) V. DiNoto, A. B. Boeer, S. Lavina, C. A. Muryn, M. Bauer, G. A. Timco, E. Negro, M. Rancan, R. E. P. Winpenny and S. Gross, Adv. Funct. Mater., 2009, 19, 3226; (d) L. Z. Chen, J. Zou, Y. M. Gao, S. Wan and M. N. Huang, J. Coord. Chem., 2011, 64, 715; (e) P. C. Guo, T. Y. Chen, X. M. Ren, W. H. Ning and W. Jin, New J. Chem., 2014, 38, 2254.

18 S. Eslava, L. Zhang, S. Esconjauregui, J. Yang, K. Vanstreels, M. R. Baklanov and E. Saiz, Chem. Mater., 2013, 25, 27. 